\title{
Comparison of safety
} between self-expanding metal stents
as a bridge to surgery and emergency surgery
based on pathology: a meta-analysis

Yang Hu, Jiajun Fan, Yifan Xv, Yingjie Hu, Yuan Ding, Zhengjie Jiang and Qingsong Tao*

\begin{abstract}
Background: To explore the long-term oncological safety of using self-expanding metal stents (SEMS) as a bridge to surgery for acute obstructive colorectal cancer by comparing the pathological results of emergency surgery (ES) with elective surgery after the placement of SEMS.

Methods: Studies comparing SEMS as a bridge to surgery with emergency surgery for acute obstructive colorectal cancer were retrieved through the databases of Pubmed, Embase, and Cochrane libraries, and a meta-analysis was conducted based on the pathological results of the two treatments. Risk ratios (OR) or mean differences (MD) with 95\% confidence intervals (Cl) were calculated for the outcomes under random effects model.

Results: A total of 27 studies were included, including 3 randomized controlled studies, 2 prospective studies, and 22 retrospective studies, with a total of 3737 patients. The presence of perineural invasion ( $R R=0.58,95 \% \mathrm{Cl} 0.48,0.71$, $P<0.00001)$, lymphovascular invasion $(R R=0.68,95 \% \mathrm{Cl} 0.47,0.99, P=0.004)$ and vascular invasion $(R R=0.66,95 \%$ $\mathrm{Cl} 0.45,0.99, \mathrm{P}=0.04$ ) in SEMS group were significantly higher than those in ES group, and there was no significant difference in lymphatic invasion ( $R R=0.92,95 \% \mathrm{Cl} 0.77,1.09, \mathrm{P}=0.33$ ). The number of lymph nodes harvested in SEMS group was significantly higher than that in $\mathrm{ES}$ group $(\mathrm{MD}=-3.18,95 \% \mathrm{Cl}-4.47,-1.90, \mathrm{P}<0.00001)$. While no significant difference was found in the number of positive lymph nodes $(\mathrm{MD}=-0.11,95 \% \mathrm{Cl}-0.63,0.42, \mathrm{P}=0.69)$ and $\mathrm{N}$ stage $[\mathrm{NO}(\mathrm{RR}=1.03,95 \% \mathrm{Cl} 0.92,1.15, \mathrm{P}=0.60), \mathrm{N} 1(\mathrm{RR}=0.99,95 \% \mathrm{Cl} 0.87,1.14, \mathrm{P}=0.91), \mathrm{N} 2(\mathrm{RR}=0.94,95 \% \mathrm{Cl}$ $0.77,1.15, P=0.53)]$.

Conclusions: SEMS implantation in patients with acute malignant obstructive colorectal cancer may lead to an increase in adverse tumor pathological characteristics, and these characteristics are mostly related to the poor prognosis of colorectal cancer. Although the adverse effect of SEMS on long-term survival has not been demonstrated, their adverse effects cannot be ignored. The use of SEMS as the preferred treatment for patients with resectable obstructive colorectal cancer remains to be carefully weighed, especially when patients are young or the surgical risk is not very high.
\end{abstract}

Keywords: Self-expanding metal stents, Bridge to surgery, Pathology, Meta-analysis

*Correspondence: qstao@seu.edu.cn

Department of General Surgery, Zhongda Hospital, School of Medicine,

Southeast University, Nanjing, Jiangsu, China

\section{Background}

Colorectal cancer is the third largest cancer and the fourth most deadly cancer worldwide today, killing more than 900,000 patients annually [1]. Intestinal obstruction occurs in $8-29 \%$ of these patients [2-3]. Once intestinal 
obstruction occurs, progress is rapid and it will quickly endanger the life of patients. The main treatment in the past was to perform emergency surgery (ES) to relieve the intestinal obstruction. However, due to the water and electrolyte balance disorders, acidosis, and infection caused by intestinal obstruction, the general condition of patients is often very poor. At the same time, the edema of abdominal tissue is serious, resulting in a significantly limited visual field and operation space. Under the influence of these factors, the mortality rates and the incidence of postoperative complications are high [3]. In recent years, self-expanding metal stents (SEMS) have been widely used to relieve intestinal obstruction caused by various benign and malignant diseases. In colorectal cancer, it can serve as a bridge leading to radical surgery for resectable tumors, as well as a palliative therapy for advanced, unresectable tumors. Due to the good general condition and adequate bowel preparation of patients after the placement of SEMS, subsequent elective surgery has obvious advantages in short-term outcomes such as length of hospital stay, primary anastomosis rate and complication rate, but there is still controversy about its long-term oncological results [4]. Several studies have observed the differences and changes of histopathological between SEMS as a bridge to surgery and emergency surgery that was associated with the prognosis of colorectal cancer [5-7]. The purpose of this meta-analysis is to explore the oncological safety of SEMS as a bridge to surgery by comparing the pathological characteristics of tumors between the two treatments.

\section{Methods}

\section{Search strategy}

Searches were performed on PubMed, Embase, and Cochrane Library until April 9, 2020. The following search terms were used for retrieval: Colonial cancer, internal construction, self-expandable metal stent. The combination of medical subject headings $(\mathrm{MeSH})$ and text words were used to search, and relevant articles and references were searched to find as many qualified studies as possible. The search strategy on PubMed is available in Additional file 1.

\section{Inclusion and exclusion criteria}

Inclusion criteria: (1) intestinal obstruction due to colorectal cancer; (2) studies compared SEMS as a bridge to surgery with emergency surgery; (3) reported at least one outcome of interest; (4) all patients involved in the study were judged to be capable of radical tumor resection before operation.

Exclusion criteria: (1) SEMS as a palliative treatment; (2) malignant intestinal obstruction caused by non-colorectal cancer; (3) repeat publication or study with the same data only keep the highest quality one.

\section{Data extraction}

According to the above inclusion and exclusion criteria, two reviewers independently evaluated the eligibility of study selection according to the title and abstract. Then the second round of screening was conducted based on the full text and the final decisions were made. If there was any disagreement between the two reviewers, a third reviewer will join and resolve the disagreement. The extracted data included first author, country, publication year, basic data of patients and tumor pathological results. For continuous variables, extracted the data directly if the data reported in the study were mean and standard deviation. Converted the data to mean or standard deviation if media, standard errors, ranges, or 95\% confidence intervals were reported. If the data was incomplete, contacted the author by email to get as much information as possible.

\section{Outcomes}

Outcomes of interest included (1) the TNM stage; (2) the pathological characteristics of the tumor, such as PNI, LVI; (3) the lymph node dissection of the patients, such as the number of lymph nodes harvested and the number of positive lymph nodes.

\section{Quality assessment}

For randomized controlled trials, bias was assessed using the Jadad scale, with a total score of 5 and 3-5 scores for high-quality studies. For prospective and retrospective studies, the Newcastle-Ottawa scale (NOS) was used for evaluation. The total NOS scores were 9, and the scores greater than 6 were considered to be of high quality.

\section{Statistical analysis}

The data were analyzed using RevMan software (Cochrane Review Manager, Version 5.3). For dichotomous variables, risk ratio (RR) and 95\% confidence intervals $(95 \% \mathrm{CI})$ were used. For continuous variables, mean difference (MD) and 95\% CI were used. Considering the inherent heterogeneity of the study, such as different selection criteria for SEMS and ES among hospitals, differences in surgical procedures, and so on, we decided to use random effects model only. Heterogeneity of the study was assessed by using the index of $\mathrm{I}^{2}, \mathrm{I}^{2}>50 \%$ considered the heterogeneity to be high. If enough studies were included, funnel plots were used to assess publication bias. $\mathrm{P}<0.05$ was considered statistically significant. 


\section{Results}

\section{Studies selected}

A total of 458 studies were retrieved according to the search strategy, including 191 studies from Pubmed, 236 studies from Embase, 17 studies from Cochrane Library and, 13 studies from other sources. After screening, 27 studies were included in the final meta-analysis. The studies screening process is shown in Fig. 1.

\section{Basic characteristics and quality}

The basic characteristics and quality evaluation of the included studies are shown in Table 1. A total of 22 studies were included in this meta-analysis, including 3 randomized controlled trials [8-10], 1 prospective study [11], and 18 retrospective studies [12-29]. A total of 1582 patients used SEMS as a bridge to surgery and 1511 patients underwent emergency surgery. All non-randomized controlled trials had NOS scores greater than 6 . The Jadad scores of the 3 randomized controlled trials were all greater than 3 . It can be considered that all included studies were of high quality.

\section{Meta-analysis of pathological results PNI (perineural invasion) (Fig. 2)}

Five $[15,18,20-22]$ of the 22 included studies reported the presence of perineural invasion in pathological specimens. The mean rate of PNI positive in the SEMS group was $48.3 \%$ and $31.1 \%$ in the ES group, and the difference was statistically significant $(R R=0.58,95 \%$ CI 0.48 , $0.71, \mathrm{P}<0.00001)$.The results of the heterogeneity test showed no significant difference between the two groups $\left(\mathrm{P}=0.46, \mathrm{I}^{2}=0 \%\right)$.

\section{LVI (lymphovascular invasion) (Fig. 3)}

Five retrospective studies [14, 22, 25, 28-29] reported the occurrence of lymphovascular invasion in pathological specimens of colorectal cancer. Veld [28] subdivided LVI into LI and VI and reported on them separately. The test for overall effect showed that RR was 0.68 (95\% CI 0.47, $0.99, \mathrm{P}=0.004$ ) suggested that the rate of LVI positive in the SEMS group was significantly higher than that in the ES group (36.1\% versus $22.7 \%$ ). There was no significant difference between the two groups $\left(\mathrm{P}=0.15, \mathrm{I}^{2}=41 \%\right)$.

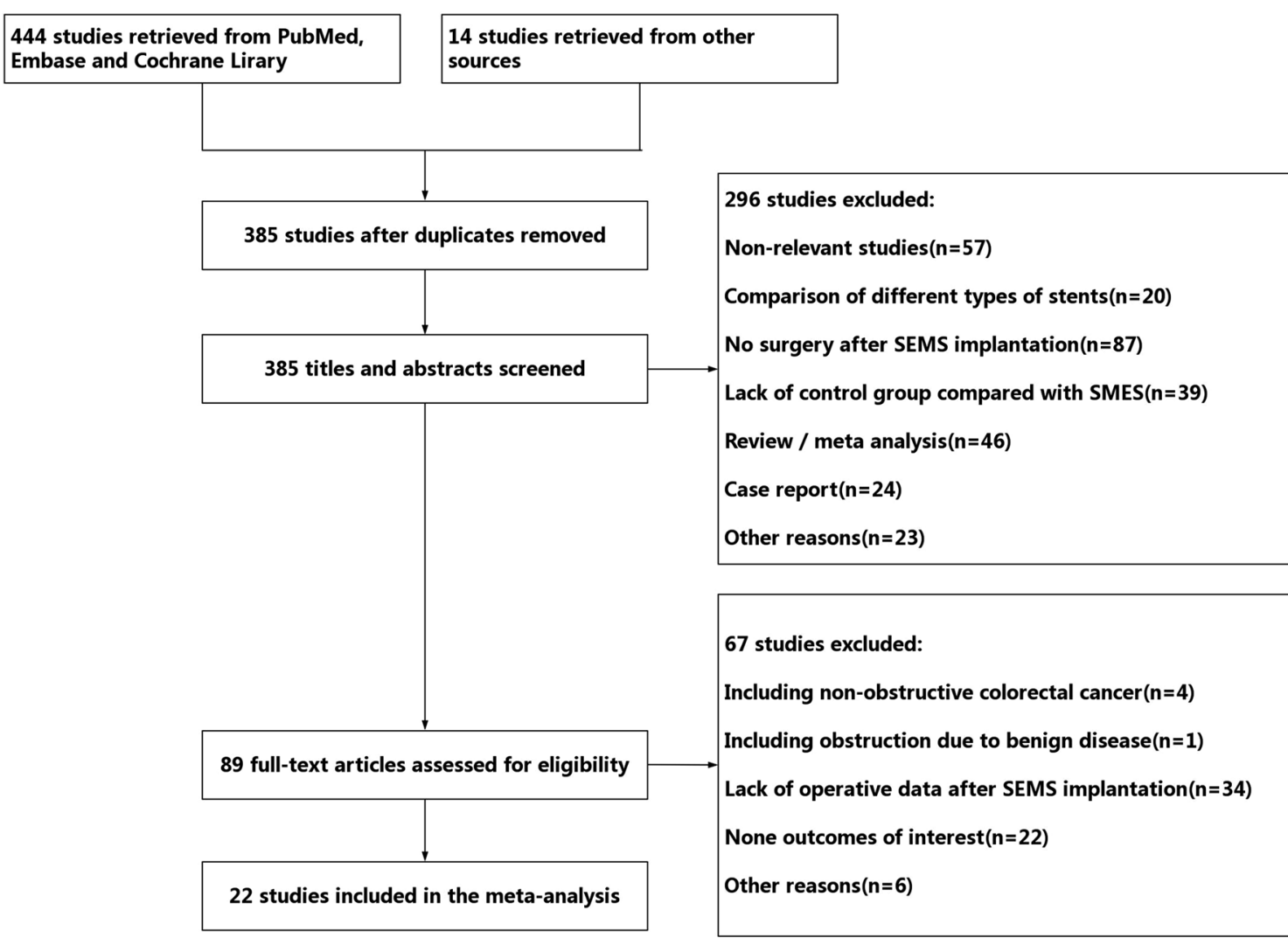

Fig. 1 Flowchart for literature inclusion 
Table 1 Basic characteristics and quality evaluation of included studies

\begin{tabular}{|c|c|c|c|c|c|c|c|c|}
\hline First author & Years & Country & Study type & Obstruction site & $\begin{array}{l}\text { Samples SEMS } \\
\text { vs ES }\end{array}$ & $\begin{array}{l}\text { Age, mean (range } \\
\text { or SD) } \\
\text { SEMS vs ES }\end{array}$ & $\begin{array}{l}\text { Gender, M/F } \\
\text { SEMS vs ES }\end{array}$ & NOS/Jadad \\
\hline Alcantara & 2011 & Spain & $\mathrm{RCT}$ & Left colon & 15 vs 13 & $\begin{array}{l}71.9(8.96) \text { vs } 71.15 \\
\quad(9)\end{array}$ & $5 / 10$ vs $7 / 6$ & 3 \\
\hline Amelung & 2016 & The Netherlands & RS & Left colon & 51 vs 37 & $\begin{array}{l}71.8(13.1) \text { vs } 66.63 \\
(13.2)\end{array}$ & $25 / 26$ vs $14 / 23$ & 7 \\
\hline Amelung & 2019 & The Netherlands & RS & Left colon & 222 vs 444 & $\begin{array}{l}72(64-80) \text { vs } 73 \\
(63-79)\end{array}$ & $124 / 98$ vs $253 / 191$ & 8 \\
\hline Arezzo & 2017 & Italy & $\mathrm{RCT}$ & Left colorectal & 56 vs 59 & $\begin{array}{l}72 \text { (43-90) vs } 71 \\
(44-94)\end{array}$ & $28 / 28$ vs $32 / 27$ & 3 \\
\hline Chen & 2019 & China & RS & Colorectal & 38 vs 90 & $\begin{array}{c}63.21(13.55) \text { vs } \\
61.58(14.84)\end{array}$ & $23 / 15$ vs $59 / 31$ & 7 \\
\hline Gorissen & 2013 & UK & PS & Left colon & 62 vs 43 & $\begin{array}{l}70.6(28-95) \text { vs } 72.0 \\
(36-96)\end{array}$ & $36 / 26$ vs $20 / 23$ & 8 \\
\hline Haraguchi & 2016 & Japan & RS & Colon & 22 vs 22 & 67 (11.0) vs 68 (10.0) & $12 / 10$ vs $15 / 7$ & 6 \\
\hline $\mathrm{Ho}$ & 2017 & China & RS & Left colon & 62 vs 40 & $\begin{array}{l}70.2(11.7) \text { vs } 70.9 \\
(11.5)\end{array}$ & $49 / 13$ vs $30 / 10$ & 6 \\
\hline $\mathrm{Ji}$ & 2017 & South Korean & RS & Right colon & 14 vs 25 & $\begin{array}{l}61.5(14.4) \text { vs } 66.9 \\
(12.4)\end{array}$ & $4 / 10$ vs $11 / 14$ & 6 \\
\hline Kang & 2018 & South Korean & RS & Left colorectal & 226 vs 109 & $\begin{array}{l}64.4(12.8) \text { vs } 64.1 \\
(14.8)\end{array}$ & $141 / 85$ vs $70 / 39$ & 8 \\
\hline Kavanagh & 2013 & Ireland & RS & Colon & 23 vs 26 & $\begin{array}{l}69.9(46-91) \text { vs } 69.7 \\
(49-89)\end{array}$ & $13 / 10$ vs $16 / 10$ & 7 \\
\hline Kim & 2013 & South Korean & RS & Left colon & 25 vs 70 & $\begin{array}{l}61.6(46-80) \text { vs } 61.7 \\
(23-90)\end{array}$ & $15 / 10$ vs $47 / 23$ & 6 \\
\hline Kim & 2015 & South Korean & RS & Colorectal & 27 vs 29 & $\begin{array}{c}64.6(57.8-71.5) \text { vs } \\
70.7(65.8-75.6)\end{array}$ & $18 / 9$ vs $16 / 13$ & 7 \\
\hline Kim & 2017 & South Korean & RS & Left colon & 158 vs 56 & $\begin{array}{l}63.9(12.5) \text { vs } 64.5 \\
(13.5)\end{array}$ & $79 / 79$ vs $30 / 26$ & 6 \\
\hline Kwak & 2016 & South Korean & RS & Left colorectal & 42 VS 42 & Not available & $28 / 14$ vs $26 / 16$ & 8 \\
\hline Oistamo & 2016 & Sweden & RS & Left colon & 20 vs 80 & Not available & Not available & 7 \\
\hline Park & 2018 & South Korean & RS & Left colorectal & 94 vs 17 & $\begin{array}{l}64.0(12.1) \text { vs } 69.0 \\
(11.5)\end{array}$ & $52 / 42$ vs $9 / 8$ & 6 \\
\hline Rodrigues & 2019 & Portugal & RS & Left colorectal & 48 vs 46 & $\begin{array}{l}67(58-76) \text { vs } 75 \\
(60-83)\end{array}$ & $25 / 23$ vs $25 / 21$ & 6 \\
\hline Sabbagh & 2013 & France & RS & Left colon & 48 vs 39 & $\begin{array}{c}69.73(13.31) \text { vs } \\
74.89(13.61)\end{array}$ & $29 / 19$ vs $20 / 19$ & 6 \\
\hline Sloothaak & 2014 & The Netherlands & $\mathrm{RCT}$ & Colon & 26 vs 32 & $\begin{array}{l}67(60-67) \text { vs } 70 \\
(61-79)\end{array}$ & $12 / 14$ vs $18 / 14$ & 3 \\
\hline Veld & 2019 & The Netherlands & RS & Left colon & 121 vs 121 & $\begin{array}{l}70.1(12.1) \text { vs } 69.8 \\
\quad(11.0)\end{array}$ & $73 / 48$ vs $72 / 29$ & 8 \\
\hline Yang & 2019 & South Korean & RS & Colon & 182 vs 71 & $\begin{array}{l}65.2(12.4) \text { vs } 63.9 \\
(14.9)\end{array}$ & $107 / 75$ vs $42 / 29$ & 6 \\
\hline
\end{tabular}

NOS for PS and RS, Jadad for RCT

$R S$ retrospective studies, $R C T$ randomized controlled trials, $P S$ prospective studies, SEMS self-expanding metal stents, ES emergency surgery

\section{VI (vascular invasion) (Fig. 4)}

A total of four studies $[15,18,21,28]$ reported the incidence of VI in the SEMS group and the ES group. The results showed that the incidence of VI was $24.8 \%$ and $17.1 \%$ in the SMES and ES groups, respectively, and the difference between the two groups was statistically significant $(R R=0.66,95 \%$ CI $0.45,0.99, P=0.04)$. No heterogeneity was found $\left(\mathrm{P}=0.12, \mathrm{I}^{2}=48 \%\right)$.

\section{LI (lymphatic invasion) (Fig. 5)}

Five studies [15, 18, 20-21, 28] reported the invasion of lymphatic vessels by tumor cells. The incidence of LI between the two groups was $38.8 \%$ and $43.8 \%$, respectively, with no significant difference exist $(R R=0.92$, 95\% CI 0.77, 1.09, $\mathrm{P}=0.33)$. Heterogeneity between these studies was low $\left(\mathrm{P}=0.33, \mathrm{I}^{2}=12 \%\right)$. 


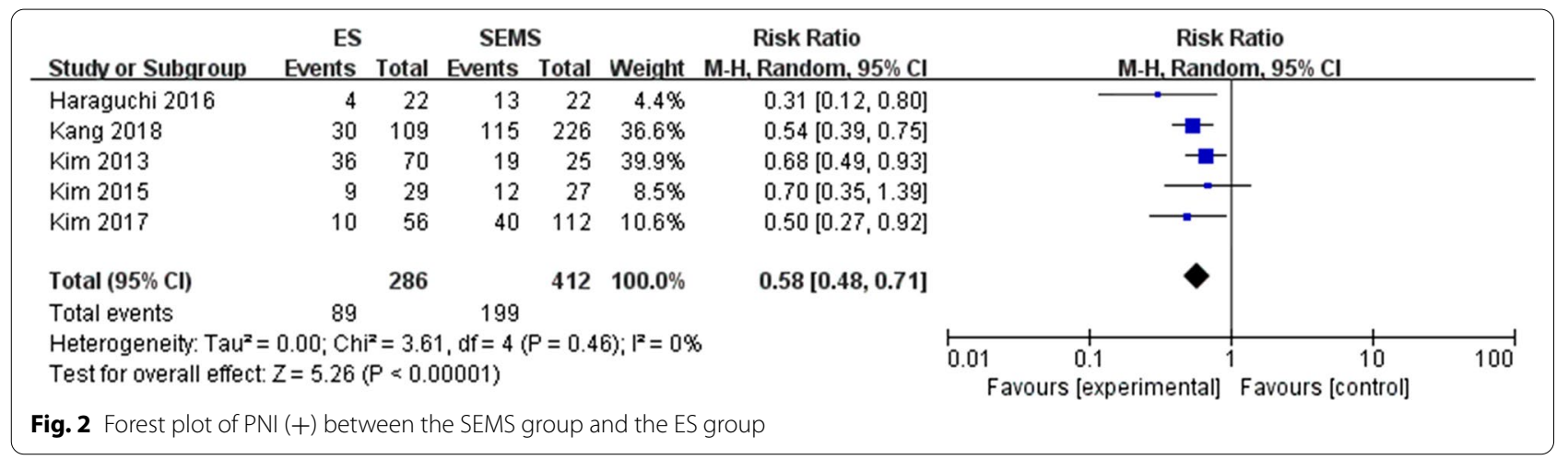

\begin{tabular}{|c|c|c|c|c|c|c|c|c|c|}
\hline Studv or Subgroup & $\begin{array}{l}\text { ES } \\
\text { Events }\end{array}$ & Total & $\begin{array}{l}\text { SEMS } \\
\text { Events }\end{array}$ & S Total & Weight & $\begin{array}{c}\text { Risk Ratio } \\
\text { M-H, Random, } 95 \% \mathrm{Cl}\end{array}$ & $\begin{array}{r}\text { Risk } \mathrm{I} \\
\text { M-H, Rando }\end{array}$ & $\begin{array}{l}\text { Ratio } \\
\text { om, } 95 \% \mathrm{Cl}\end{array}$ & \\
\hline Chen 2019 & 15 & 90 & 14 & 38 & $21.1 \%$ & $0.45[0.24,0.84]$ & $\longrightarrow$ & & \\
\hline Kim 2015 & 5 & 29 & 4 & 27 & $8.0 \%$ & $1.16[0.35,3.89]$ & & & \\
\hline Park 2018 & 3 & 17 & 48 & 94 & $10.2 \%$ & $0.35[0.12,0.98]$ & & & \\
\hline Veld 2019 & 31 & 106 & 34 & 113 & $31.8 \%$ & $0.97[0.65,1.46]$ & & & \\
\hline Yang 2019 & 17 & 71 & 64 & 182 & $28.9 \%$ & $0.68[0.43,1.08]$ & $=-$ & & \\
\hline Total $(95 \% \mathrm{Cl})$ & & 313 & & 454 & $100.0 \%$ & $0.68[0.47,0.99]$ & & & \\
\hline Total events & 71 & & 164 & & & & & & \\
\hline \multicolumn{7}{|c|}{$\begin{array}{l}\text { Heterogeneity: } \mathrm{Tau}^{2}=0.07 ; \mathrm{Chi}^{2}=6.82, \mathrm{df}=4(P=0.15) ; \mathrm{l}^{2}=41 \% \\
\text { Test for overall effect: } Z=2.02(P=0.04)\end{array}$} & $\begin{array}{|cc|}0.01 & 0.1 \\
& \text { Favours [experimental] }\end{array}$ & Favours [control] & 100 \\
\hline
\end{tabular}

\begin{tabular}{|c|c|c|c|c|c|c|c|c|c|}
\hline Study or Subgroup & $\begin{array}{r}\text { ES } \\
\text { Events }\end{array}$ & Total & $\begin{array}{l}\text { SEMS } \\
\text { Events }\end{array}$ & S Total & Weight & $\begin{array}{c}\text { Risk Ratio } \\
\text { M-H, Random, } 95 \% \mathrm{Cl}\end{array}$ & $\begin{array}{r}\text { Risk I } \\
\text { M-H, Rando }\end{array}$ & $\begin{array}{l}\text { Ratio } \\
\text { dom, } 95 \% \mathrm{Cl}\end{array}$ & \\
\hline Haraguchi 2016 & 15 & 22 & 17 & 22 & $38.3 \%$ & $0.88[0.61,1.27]$ & & & \\
\hline Kang 2018 & 20 & 109 & 60 & 226 & $32.7 \%$ & $0.69[0.44,1.09]$ & & & \\
\hline Kim 2017 & 0 & 56 & 7 & 112 & $1.9 \%$ & $0.13[0.01,2.27]$ & - & & \\
\hline Veld 2019 & 15 & 106 & 33 & 111 & $27.2 \%$ & $0.48[0.27,0.82]$ & & & \\
\hline Total $(95 \% \mathrm{Cl})$ & & 293 & & 471 & $100.0 \%$ & $0.66[0.45,0.99]$ & & & \\
\hline Total events & 50 & & 117 & & & & & & \\
\hline \multicolumn{7}{|c|}{$\begin{array}{l}\text { Heterogeneity: } \mathrm{Tau}^{2}=0.07 ; \mathrm{Chi}^{2}=5.81, \mathrm{df}=3(\mathrm{P}=0.12) ; \mathrm{I}^{2}=48 \% \\
\text { Test for overall effect: } Z=2.02(P=0.04)\end{array}$} & $\begin{array}{ll}0.01 & 0.1 \\
\quad \text { Favours [experimental] }\end{array}$ & 1 Favours [control] & 100 \\
\hline
\end{tabular}

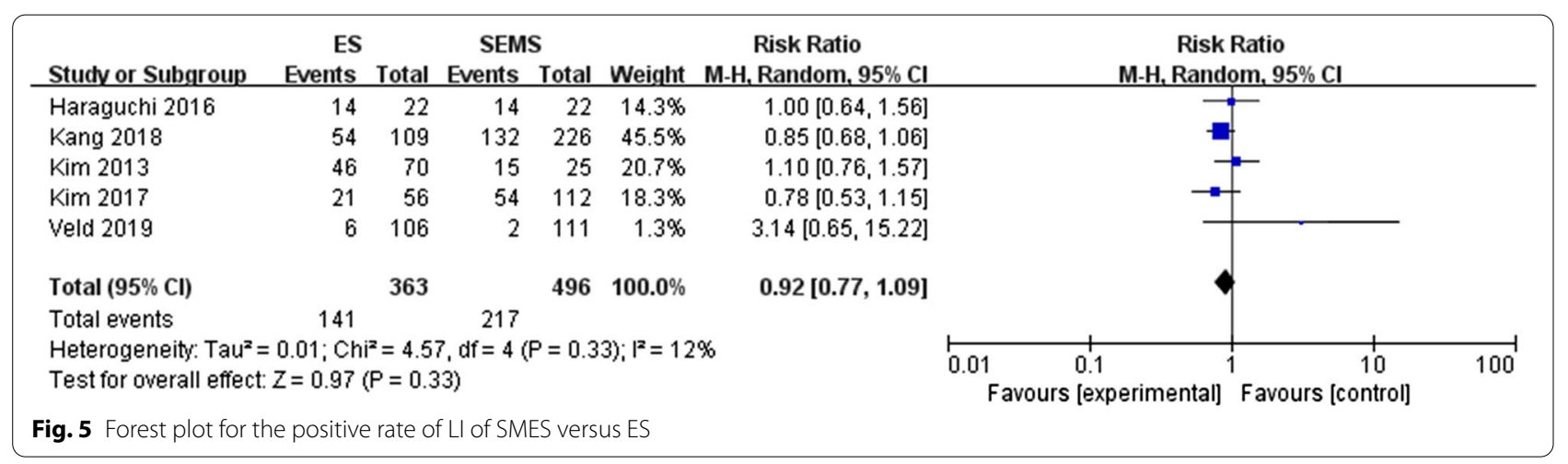




\section{Lymph nodes harvested (Fig. 6)}

A total of seventeen [8-10, 12-15, 17-20, 23-28] studies reported the number of lymph nodes dissection. The results showed that elective surgery after the placement of SEMS harvested significantly more lymph nodes than emergency surgery $(\mathrm{MD}=-3.18,95 \% \mathrm{CI}-4.47,-1.90$, $\mathrm{P}<0.00001)$ with significant heterogeneity among these studies $\left(\mathrm{P}=0.0001, \mathrm{I}^{2}=65 \%\right)$.

\section{Positive lymph nodes (Fig. 7)}

Five studies $[9-10,19,25,28]$ reported the number of positive lymph nodes. There was no significant difference between the two groups ( $\mathrm{MD}=-0.11,95 \% \mathrm{CI}--0.63$, $0.42, \mathrm{P}=0.69)$, and no heterogeneity was observed $\left(\mathrm{P}=0.71, \mathrm{I}^{2}=0 \%\right)$.

\section{N stage (Fig. 8)}

A total of eight studies [8,11-12, 14, 16, 25, 28-29] reported the $\mathrm{N}$ stage of TNM stage in detail. In this meta-analysis N0, N1 and N2 were analyzed respectively, and the results showed that there was no significant difference between the SEMS group and the ES group in the $\mathrm{N}$ stage. N0 $(\mathrm{RR}=1.03,95 \% \mathrm{CI} 0.92$, $1.15, \mathrm{P}=0.60$ and $\mathrm{P}=0.92, \mathrm{I}^{2}=0 \%$ for heterogeneity), $\mathrm{N} 1(\mathrm{RR}=0.99,95 \% \mathrm{CI} 0.87,1.14, \mathrm{P}=0.91$ and $\mathrm{P}=0.16$, $\mathrm{I}^{2}=33 \%$ for heterogeneity), $\mathrm{N} 2(\mathrm{RR}=0.94,95 \% \mathrm{CI} 0.77$, $1.15, \mathrm{P}=0.53$ and $\mathrm{P}=0.83, \mathrm{I}^{2}=0 \%$ for heterogeneity).

\section{Publication bias and sensitivity analysis}

The funnel plots of outcomes with more than 5 studies included are shown in Fig. 9. The results showed that the data were not distributed symmetrically, suggesting the possibility of publication bias. After excluding individual studies one by one, the effect values of the remaining studies and the original effect values did not change significantly, suggesting that the results are relatively stable.

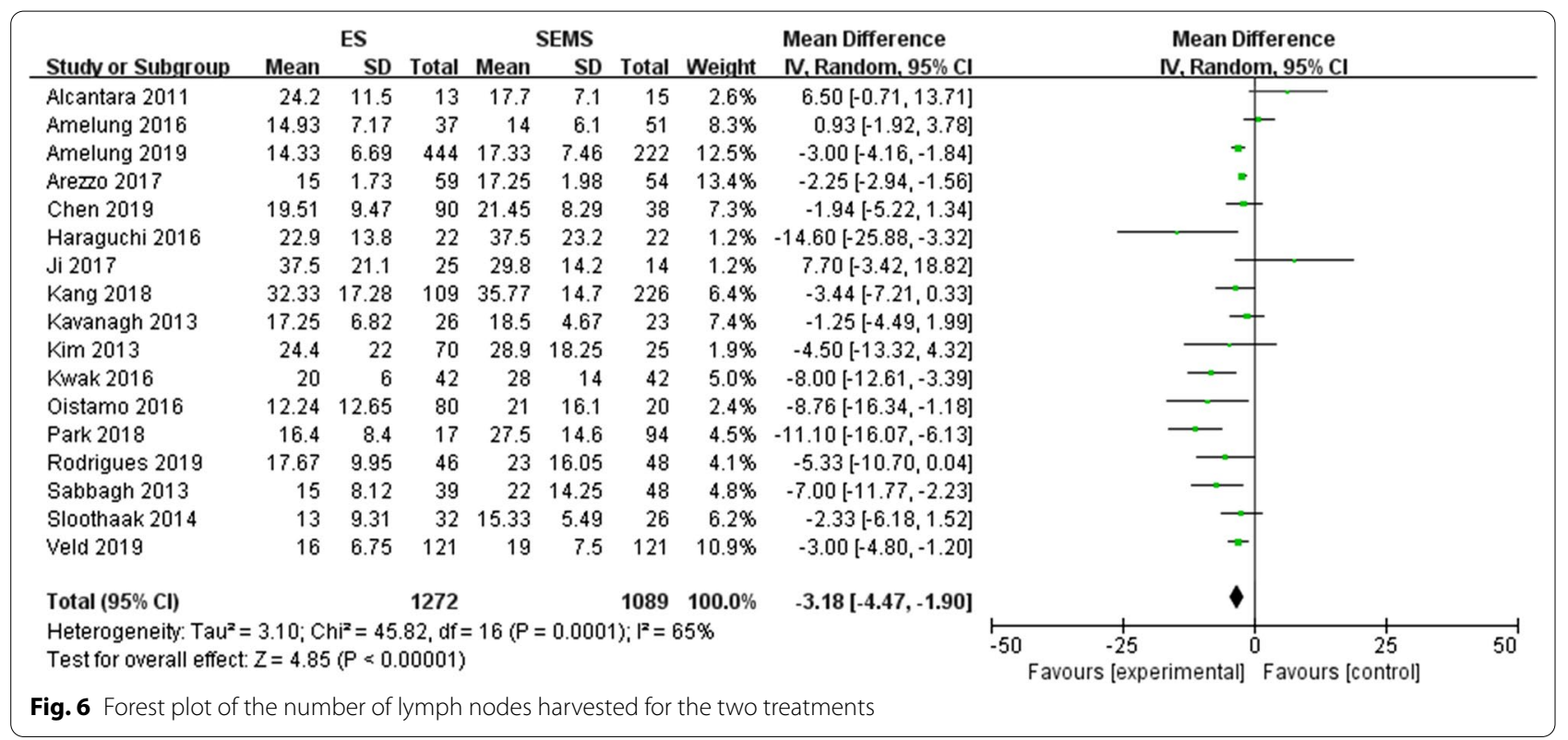

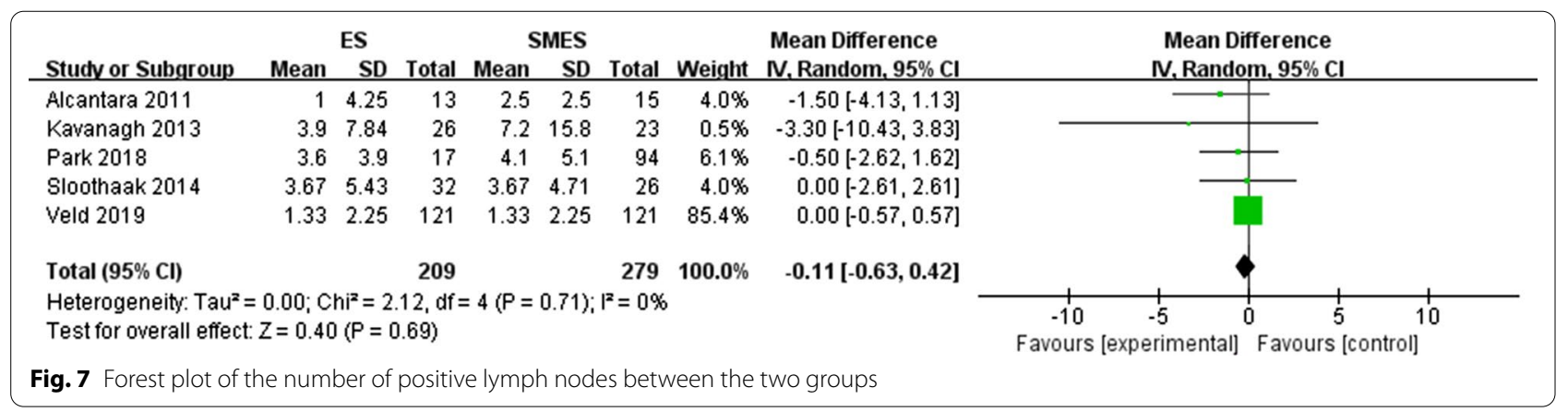




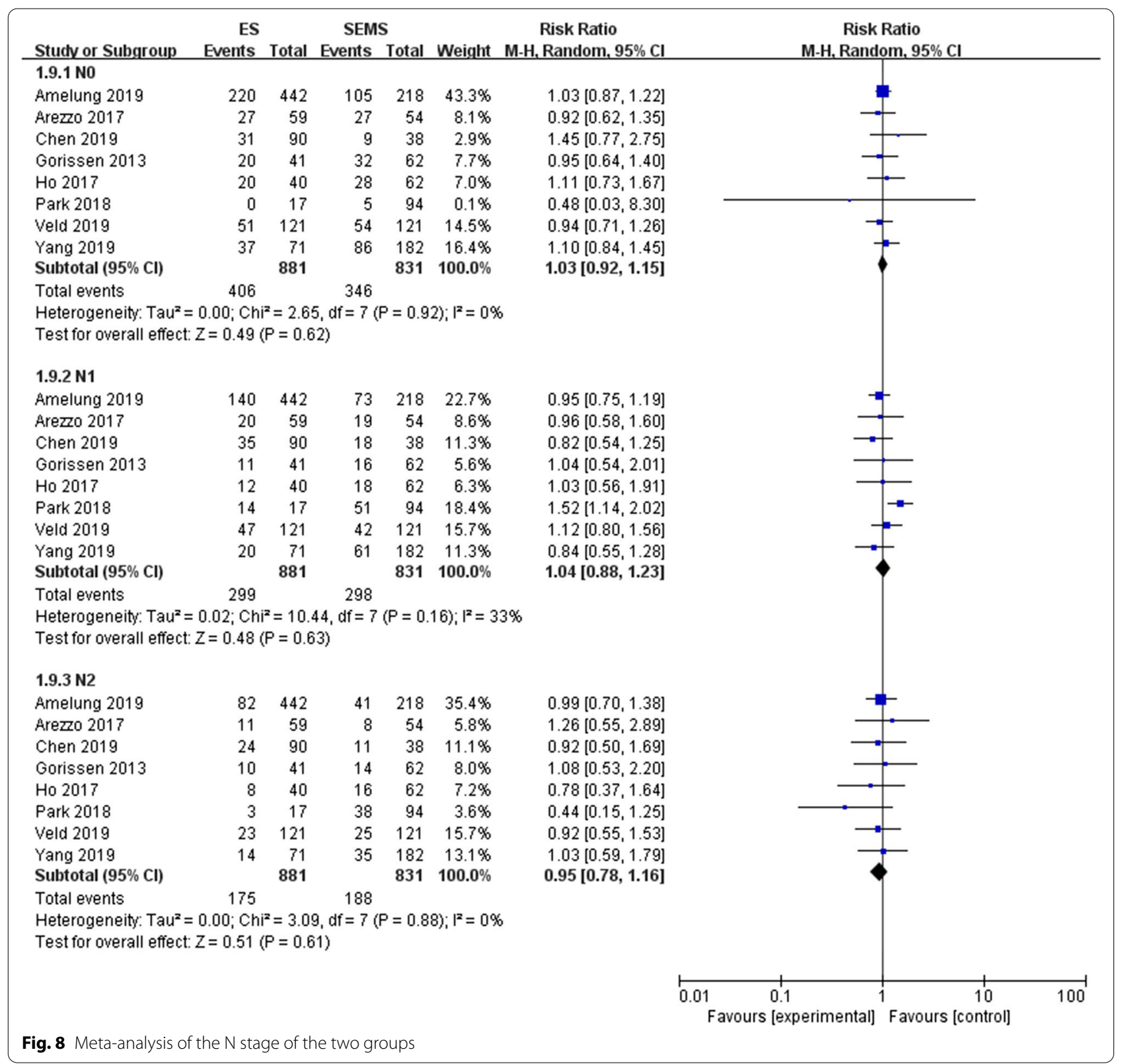

\section{Discussion}

For resectable colorectal cancer, when acute intestinal obstruction occurs, there are currently three main treatment: (1) emergency surgical resection of the tumor, and stoma should be decided according to the patient's condition; (2) elective surgical resection of the tumor after emergency stoma to relieve the intestinal obstruction; (3) elective surgical resection of the tumor after the placement of SEMS. Once intestinal obstruction occurs, there is a high risk of emergency surgery due to various factors such as water-electrolyte balance disorder, acid-base balance disorder, and bacterial translocation, and the mortality rate can be up to 15\% [30]. Since the first reported use of SEMS in 1991, SEMS as a bridge of surgery has been widely developed because of its good short-term results, but its long-term oncology results are worrying [4]. Several studies [31-34] have found that SEMS implantation can cause tumor cells to release into the circulatory system, but Ishibashi [31] believes that these tumor cells are not cancer stem-like cells, which can be quickly removed by the body, so they will not cause distant metastasis of the tumor. Some scholars [5-6] also observed many adverse histopathological changes after SEMS implantation, including tumor 

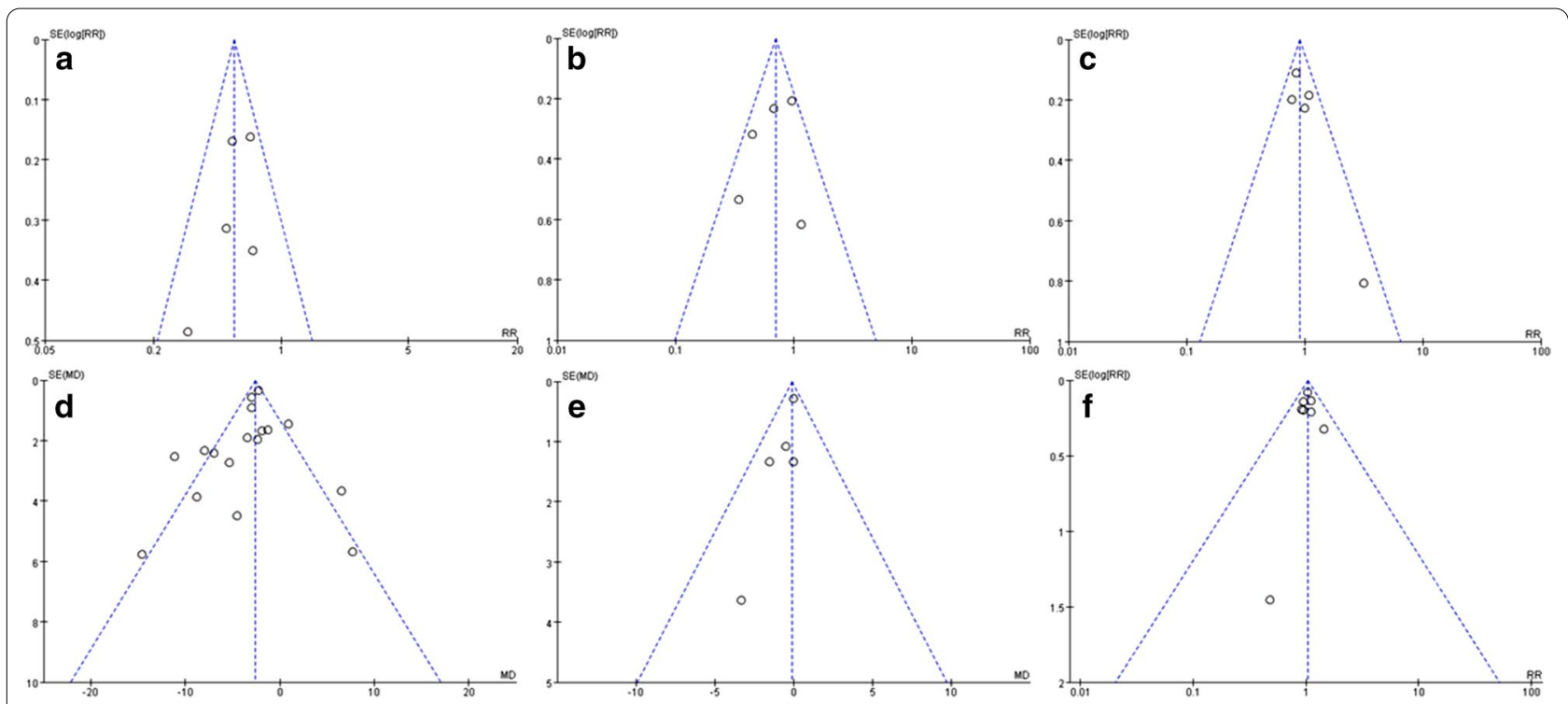

Fig. 9 Funnel plots of outcomes a PNI, b LVI, $\mathbf{c} L I$, d lymph nodes harvested, e positive lymph nodes, $\mathbf{f} \mathrm{N}$ stage

ulceration, perineural invasion, and lymph node metastasis. However, Matsuda [35] found that the increase of tumor p27kip1 expression level and the decrease of Ki-67 expression level after SEMS insertion, suggesting that the increase of mechanical pressure caused by SEMS may inhibit the proliferation of tumor. In the study of cancer recurrence and disease-free survival rate, etc., the results were also contradictory. Most scholars [20, 36-37] have not observed the difference between the SEMS group and the ES group, while Gorissen [11] believed that SEMS can increase the local recurrence rate of cancer. Sabbagh [27] found the SEMS group was inferior to the ES group in long-term outcomes such as overall survival and cancer-specific mortality apparently. In this meta-analysis, we compared the pathological characteristics of neoplasm between the two treatments to explore the potential oncological results of SEMS as a bridge to surgery.

Perineural invasion is a special pathological feature of many malignant tumors, and the current mainstream view is that PNI refers to the discovery of tumor cells in any of the three layers of nerve structure [38-39]. In colorectal cancer, many scholars believe that PNI positive is an independent prognostic factor for poor prognosis, such as less survival time, shorter recurrence time, and increased local recurrence rate [40-44]. Liebig's [45] research showed that the 5-year disease-free survival rate of PNI negative patients was 4 times higher than that of PNI positive patients, and a previous meta-analysis [46] showed that PNI positive patients with stage II colorectal cancer had a similar postoperative survival to stage III patients. Nozawa [42] found that the increase of mechanical pressure may lead to the development of PNI, and that the SEMS can relieve the intestinal obstruction by expanding the part of the intestine that contains the tumor, no doubt increasing the pressure in that part of the intestine. Many studies have observed a higher PNI positive rate in patients with SEMS [6-7]. The results of this meta-analysis also showed that the PNI positive rate in the SEMS group was significantly higher than that in the ES group. At present, there is no sufficient explanation for the higher PNI positive rate after SEMS implantation, and the increase of mechanical pressure may be one reason. Theoretically, as a recognized independent prognostic factor for colorectal cancer, a higher PNI positive rate would result in a worse prognosis. However, no significant difference was found between the two groups in most studies, which may be due to the following reasons. Firstly, the proportion of postoperative adjuvant chemotherapy is greatly increased due to the acute intestinal obstruction. Previous studies suggested that PNI positive patients could achieve similar survival outcomes as PNI negative patients through adjuvant chemotherapy $[43,46]$. Perhaps benefiting from adjuvant chemotherapy, the SEMS group and the ES group achieved similar long-term oncology outcomes. Secondly, the time interval between the placement of SEMS and elective surgery is usually between 5 and 10 days [47], SEMS may lead to more PNI, but the time interval is too short, and the tumor has been radical resected before it can be converted into the effect on long-term oncology results. Besides, since these invaded cells may not be cancer stem cells, have a low malignant potential and maybe quickly recognized and cleared by the body, and therefore do not affect the prognosis of patients. Finally, previous 
studies have found that mechanical pressure can inhibit the proliferation of tumor cells, while similar phenomena have been observed after SMES implantation [35], and patients may benefit from this to a certain extent.

Lymphovascular invasion refers to the structure of lymphatic or blood vessels invaded by tumor cells, so it can be divided into lymphatic invasion and vascular invasion. Due to the high difficulty in accurately distinguishing lymphatic and vascular in pathological specimens, lymphovascular invasion is generally reported uniformly. In colorectal cancer, lymphovascular invasion is considered to be an independent predictor of poor prognosis [48-49]. It is not only associated with higher T stage and poor differentiation, but also a key link of distant metastasis, and an important risk factor for cancer recurrence and shortened survival [50-52]. In this meta-analysis, we observed a higher rate of lymphovascular invasion in the SEMS group. Some studies suggested that lymphatic invasion and vascular invasion may have different effects on tumors. Compared with lymphatic invasion, vascular invasion is more likely to lead to viscera metastasis [5354]. The survival time of patients with positive vascular invasion is much lower than that of negative patients, and the number of vascular invasion is positively correlated with recurrence [55-56]. In our meta-analysis, 5 studies reported lymphatic invasion and 4 studies reported vascular invasion respectively, and the results showed that no significant difference was found in lymphatic invasion, while the positive rate of vascular invasion in the SEMS group was significantly higher than that in the ES group. In theory, the prognosis of SEMS group with more lymphovascular invasion or vascular invasion should be worse, but perhaps as with PNI, there is no significant difference in the long-term outcomes between the two groups due to adjuvant chemotherapy, short time interval, non-cancer stem cells invaded and other reasons, but considering the potential adverse effects, SEMS should not be considered as the preferred treatment.

Accurate pathological stage is very important for guiding the postoperative treatment of colorectal cancer, and sufficient lymph nodes dissection is one of the decisive factors to judge the stage of cancer. When the number of lymph nodes in the resected surgical specimens is insufficient, the pathological stage of cancer may be misjudged and the patient cannot receive effective follow-up adjuvant therapy. Meanwhile, the lymph nodes that have been invaded may be omitted, which may lead to the recurrence of cancer and other adverse outcomes. The current study suggests that a low number of lymph nodes harvested can lead to poor prognosis of colorectal cancer. In the emergency surgery for obstructive colorectal cancer, due to severe intestinal dilatation at the upper end of the obstruction and edema of abdominal tissue, the operative field is usually poor, and the difficulty of tissue separation and exposure increases. The placement of SEMS can effectively restore the intestinal patency and make the abdominal tissue edema subside, thus providing a good surgical field of vision. Moreover, the general situation of patients after stent implantation improved significantly, which made the laparoscopy rate in the SEMS group much higher than that in the ES group. The operative field of vision under laparoscopy was broader, which can more clearly show the anatomical structures that are difficult to expose in open surgery. This may explain that in most studies, the number of harvested lymph nodes in the SEMS group was higher than that in the ES group, and our meta-analysis showed the same results. However, there is no significant difference in the number of positive lymph nodes in the meta-analysis. The current guidelines suggest that the number of lymph nodes to be harvested should be more than 12 [57], and most of the included studies were significantly higher than this requirement. At this time, the difference in the number of lymph nodes harvested between the two groups may not affect the pathological stage of patients. This was also confirmed by the meta-analysis of the $\mathrm{N}$ stage. Therefore, although the SEMS group has a significant advantage in the number of lymph nodes harvested, this advantage may be of limited significance.

There is no doubt that SEMS, as a bridge to surgery, is superior to emergency surgery in terms of some short outcomes such as primary anastomosis, complications, and permanent stoma rate [4], but its histopathological performance is significantly inferior to emergency surgery. The complications of SEMS placement also can not be ignored. Perforation, as the most serious complication, will not only cause peritoneal dissemination of tumors, but also be the main cause of early death. According to the literature, its incidence is as high as $7.4 \%$, while the rate of occult perforation is higher $[5,58]$. Overall survival (OS) and disease-free survival (DFS) are the most commonly used indicators to evaluate the prognosis of cancer patients. A recent literature review showed that only a small number of studies showed that the placement of SEMS may affect the long-term surgical outcomes, and most studies showed that SEMS did not have a negative impact on the patients' long-term survival and prognosis [59]. Two recent meta-analyses respectively summarize the data of 2508 patients and 15,224 patients, the results showed no significant difference between SEMS and ES in terms of three-year OS and three-year DFS, or fiveyear OS and five-year DFS, which was consistent with the results of previous meta-analysis [59-61]. However, given the relatively small proportion of randomized controlled studies (20.8\% and $26.7 \%$ respectively), and 
the factors such as stent placement technology and stent type can not be standardized, and due to the possible influence of factors such as chemotherapy and surgical interval mentioned above, the absence of significant differences in long-term surgical outcomes should be interpreted with caution. In summary, there is a risk of using SEMS as the preferred treatment for patients with resectable tumors. The European Society of Gastrointestinal Endoscopy (ESGE) has not recommended the routine use of SEMS as a bridge to elective surgery for left-sided malignant intestinal obstruction, but SEMS can be considered as a bridge for elective surgery in potentially curable patients ASA $\geq$ III and/or age $>70$ years [47].

This meta-analysis compared the pathological characteristics of the SEMS group and the ES group to explore the long-term oncology safety of SEMS as a surgical bridge, but many limitations of this study may affect the interpretation of the results. First, twenty-two of the 27 studies were retrospective (about 81.5\%) with inherent limitations, and its' large proportion required careful interpretation of the results. Furthermore, the three included RCTs also failed to achieve blind allocation between doctors and patients. Secondly, there was high heterogeneity among studies, such as different types of self-expanding metal stents, the proficiency of endoscopists, the experience of the center, different emergency surgical procedures in different hospitals, and different selection criteria for SEMS and emergency surgery, etc. Third, the definition of some pathological features is currently controversial. For example, PNI may be missed or misreported due to the inconsistent definition, and the authenticity of the results may be affected. A similar situation may also exist in LVI.

\section{Conclusions}

After the placement of SEMS, some important pathological features that affect the prognosis of patients, such as perineural invasion, lymphovascular infiltration, etc., increased significantly. Although it may not affect the long-term survival of patients under the influence of multiple factors, the benefits and risks of using SEMS as the preferred treatment for resectable colorectal cancer should be carefully weighed. At present, surgical techniques and instruments have made great progress. When patients are young or the surgical risk is not very high, emergency surgery may make patients obtain better oncological outcomes due to possible adverse effects of SEMS. For patients with an increased risk of postoperative mortality, SEMS as a bridge to elective surgery may achieve greater benefits than emergency surgery.

\section{Supplementary information}

Supplementary information accompanies this paper at https://doi. org/10.1186/s12893-020-00908-3.

Additional file 1: Search strategy on PubMed

\section{Abbreviations}

SEMS: Self-expanding metal stents; ES: Emergency surgery; NOS: Newcastle-Ottawa scale; PNI: Perineural invasion; LVI: Lymphovascular invasion; VI: Vascular invasion; LI: Lymphatic invasion; Cl: Confidence interval; MD: Mean differences; RR: Risk ratio.

\section{Acknowledgements}

We acknowledge the authors of each study. We also acknowledge Southeast University for supporting us with the access to some database.

\section{Authors' contributions}

YH and QST conceived and designed the study. YD, YH and YJH conducted literature search. YH and JJF performed data extraction, quality assessment, statistical analysis, and wrote the manuscript. YFX and ZJJ provided critical revisions that are important for the intellectual content. All authors read and approved the final version of the manuscript.

\section{Funding}

No funding support.

\section{Availability of data and materials}

All data generated or analysed during this study are included in this published article.

\section{Ethics approval and consent to participate}

Not applicable.

\section{Consent for publication}

Not applicable.

\section{Competing interests}

No conflict of interest exists.

Received: 15 July 2020 Accepted: 12 October 2020

Published online: 27 October 2020

\section{References}

1. Dekker E, Tanis PJ, Vleugels JLA, Kasi PM, Wallace MB. Colorectal cancer. Lancet. 2019;394(10207):1467-80.

2. Malakorn S, Stein SL, Lee JH, You YN. Urgent management of obstructing colorectal cancer: divert, stent, or resect? J Gastrointest Surg. 2019:23(2):425-32.

3. Schwenter F, Morel P, Gervaz P. Management of obstructive and perforated colorectal cancer. Expert Rev Anticancer Ther. 2010;10(10):1613-9.

4. Ormando VM, Palma R, Fugazza A, Repici A. Colonic stents for malignant bowel obstruction: current status and future prospects. Expert Rev Med Devices. 2019;16(12):1053-61.

5. Fryer E, Gorissen KJ, Wang LM, Guy R, Chetty R. Spectrum of histopathological changes encountered in stented colorectal carcinomas. Histopathology. 2015;66(4):480-4.

6. Sabbagh C, Chatelain D, Trouillet N, Mauvais F, Bendjaballah S, Browet F, et al. Does use of a metallic colon stent as a bridge to surgery modify the pathology data in patients with colonic obstruction? A case-matched study. Surg Endosc. 2013;27(10):3622-31.

7. Kim HJ, Choi G, Park JS, Park SY, Jun SH. Higher rate of perineural invasion in stent-laparoscopic approach in comparison to emergent open resection for obstructing left-sided colon cancer. Int J Colorectal Dis. 2013a;28(3):407-14

8. Arezzo A, Balague C, Targarona E, Borghi F, Giraudo G, Ghezzo L, et al. Colonic stenting as a bridge to surgery versus emergency surgery for 
malignant colonic obstruction: results of a multicentre randomised controlled trial (ESCO trial). Surg Endosc. 2017;31 (8):3297-305.

9. Alcantara M, Serra-Aracil X, Falco J, Mora L, Bombardo J, Navarro S. Prospective, controlled, randomized study of intraoperative colonic lavage versus stent placement in obstructive left-sided colonic cancer. World J Surg. 2011;35(8):1904-10.

10. Sloothaak DA, van den Berg MW, Dijkgraaf MG, Fockens P, Tanis PJ, van Hooft JE, et al. Oncological outcome of malignant colonic obstruction in the Dutch Stent-In 2 trial. Br J Surg. 2014;101(13):1751-7.

11. Gorissen KJ, Tuynman JB, Fryer E, Wang L, Uberoi R, Jones OM, et al. Local recurrence after stenting for obstructing left-sided colonic cancer. Br J Surg. 2013;100(13):1805-9.

12. Amelung FJ, Borstlap W, Consten E, Veld JV, van Halsema EE, Bemelman WA, et al. Propensity score-matched analysis of oncological outcome between stent as bridge to surgery and emergency resection in patients with malignant left-sided colonic obstruction. Br J Surg. 2019;106(8):1075-86.

13. Amelung FJ, Ter Borg F, Consten EC, Siersema PD, Draaisma WA. Deviating colostomy construction versus stent placement as bridge to surgery for malignant left-sided colonic obstruction. Surg Endosc. 2016;30(12):5345-55.

14. Chen XQ, Xue CR, Hou P, Lin BQ, Zhang JR. Lymphocyte-to-monocyte ratio effectively predicts survival outcome of patients with obstructive colorectal cancer. World J Gastroenterol. 2019;25(33):4970-84.

15. Haraguchi N, Ikeda M, Miyake M, Yamada T, Sakakibara Y, Mita E, et al. Colonic stenting as a bridge to surgery for obstructive colorectal cancer: advantages and disadvantages. Surg Today. 2016;46(11):1310-7.

16. Ho KM, Chan KM, Kwok SY, Lau PYY. Colonic self-expanding metal stent (SEMS) as a bridge to surgery in left-sided malignant colonic obstruction: an 8-year review. Surg Endosc. 2017;31(5):2255-62.

17. Ji WB, Kwak JM, Kang DW, Kwak HD, Um JW, Lee SI, et al. Clinical benefits and oncologic equivalence of self-expandable metallic stent insertion for right-sided malignant colonic obstruction. Surg Endosc. 2017;31(1):153-8

18. Kang SI, Oh HK, Yoo JS, Ahn S, Kim MH, Kim MJ, et al. Oncologic outcomes of preoperative stent insertion first versus immediate surgery for obstructing left-sided colorectal cancer. Surg Oncol. 2018;27(2):216-24.

19. Kavanagh DO, Nolan B, Judge C, Hyland JM, Mulcahy HE, O'Connell $\mathrm{PR}$, et al. A comparative study of short- and medium-term outcomes comparing emergent surgery and stenting as a bridge to surgery in patients with acute malignant colonic obstruction. Dis Colon Rectum. 2013;56(4):433-40.

20. Kim HJ, Choi GS, Park JS, Park SY, Jun SH. Higher rate of perineural invasion in stent-laparoscopic approach in comparison to emergent open resection for obstructing left-sided colon cancer. Int J Colorectal Dis. 2013b;28(3):407-14.

21. Kim MK, Kye BH, Lee IK, Oh ST, Ahn CH, Lee YS, et al. Outcome of bridge to surgery stenting for obstructive left colon cancer. ANZ J Surg. 2017;87(12):E245-50.

22. Kim SJ, Kim HW, Park SB, Kang DH, Choi CW, Song BJ, et al. Colonic perforation either during or after stent insertion as a bridge to surgery for malignant colorectal obstruction increases the risk of peritoneal seeding. Surg Endosc. 2015;29(12):3499-506.

23. Kwak MS, Kim WS, Lee JM, Yang DH, Yoon YS, Yu CS, et al. Does stenting as a bridge to surgery in left-sided colorectal cancer obstruction really worsen oncological outcomes? Dis Colon Rectum. 2016;59(8):725-32.

24. Oistamo E, Hjern F, Blomqvist L, Falken Y, Pekkari K, Abraham-Nordling M. Emergency management with resection versus proximal stoma or stent treatment and planned resection in malignant left-sided colon obstruction. World J Surg Oncol. 2016;14(1):232.

25. Park J, Lee HJ, Park SJ, Hur H, Min BS, Cheon JH, et al. Long-term outcomes after stenting as a bridge to surgery in patients with obstructing left-sided colorectal cancer. Int J Colorectal Dis. 2018;33(6):799-807.

26. Rodrigues-Pinto E, Morais R, Coelho C, Pereira P, Repici A, Macedo G Bridge-to-surgery versus emergency surgery in the management of left-sided acute malignant colorectal obstruction-efficacy, safety and long-term outcomes. Dig Liver Dis. 2019;51(3):364-72.

27. Sabbagh C, Browet F, Diouf M, Cosse C, Brehant O, Bartoli E, et al. Is stenting as "a bridge to surgery" an oncologically safe strategy for the management of acute, left-sided, malignant, colonic obstruction? A comparative study with a propensity score analysis. Ann Surg. 2013;258(1):107-15.
28. Veld JV, Amelung FJ, Borstlap W, Van Halsema EE, Consten E, Siersema PD, et al. Comparison of decompressing stoma vs stent as a bridge tosurgery for left-sided obstructive colon cancer. JAMA Surg. 2020;155(3):206-15.

29. Yang SY, Park YY, Han YD, Cho MS, Hur H, Min BS, et al. Oncologic outcomes of self-expandable metallic stent as a bridge to surgery and safety and feasibility of minimally invasive surgery for acute malignant colonic obstruction. Ann Surg Oncol. 2019;26(9):2787-96.

30. Kaya S, Seker A, Altin O, Altuntas YE, Kaptanoglu L, Kement M, et al. Evaluation of current therapeutic approach to obstructive and perforated colorectal cancers. Ulus Travma Acil Cerrahi Derg. 2019;25(6):589-96.

31. Ishibashi R, Yoshida S, Odawara N, Kishikawa T, Kondo R, Nakada A, et al. Detection of circulating colorectal cancer cells by a custom microfluid system before and after endoscopic metallic stent placement. Oncol Lett. 2019;18(6):6397-404.

32. Maruthachalam K, Lash GE, Shenton BK, Horgan AF. Tumour cell dissemination following endoscopic stent insertion. Br J Surg. 2007:94(9):1151-4.

33. Takahashi G, Yamada T, Iwai T, Takeda K, Koizumi M, Shinji S, et al. Oncological assessment of stent placement for obstructive colorectal cancer from circulating cell-free DNA and circulating tumor DNA dynamics. Ann Surg Oncol. 2018;25(3):737-44.

34. Yamashita S, Tanemura M, Sawada G, Moon J, Shimizu Y, Yamaguchi T, et al. Impact of endoscopic stent insertion on detection of viable circulating tumor cells from obstructive colorectal cancer. Oncol Lett. 2018;15(1):400-6

35. Matsuda A, Miyashita M, Matsumoto S, Sakurazawa N, Kawano Y, Yamahatsu K, et al. Colonic stent-induced mechanical compression may suppress cancer cell proliferation in malignant large bowel obstruction. Surg Endosc. 2019;33(4):1290-7.

36. Crespi-Mir A, Romero-Marcos JM, de la Llave-Serralvo A, Dolz-Abadia C, Cifuentes-Rodenas JA. Impact on surgical and oncological results of the use of colonic stents as a bridge to surgery for potentially curable occlusive colorectal neoplasms. Cir Esp. 2018;96(7):419-28.

37. Cao Y, Gu J, Deng S, Li J, Wu K, Cai K. Long-term tumour outcomes of self-expanding metal stents as "bridge to surgery" for the treatment of colorectal cancer with malignant obstruction: a systematic review and meta-analysis. Int J Colorectal Dis. 2019a;34(11):1827-38.

38. Bakst RL, Wong RJ. Mechanisms of perineural invasion. J Neurol Surg B Skull Base. 2016;77(2):96-106.

39. Marchesi F, Piemonti L, Mantovani A, Allavena P. Molecular mechanisms of perineural invasion, a forgotten pathway of dissemination and metastasis. Cytokine Growth Factor Rev. 2010;21 (1):77-82.

40. Alotaibi AM, Lee JL, Kim J, Lim SB, Yu CS, Kim TW, et al. Prognostic and oncologic significance of perineural invasion in sporadic colorectal cancer. Ann Surg Oncol. 2017;24(6):1626-34.

41. Huh JW, Lee WY, Shin JK, Park YA, Cho YB, Kim HC, et al. A novel histologic grading system based on lymphovascular invasion, perineural invasion, and tumor budding in colorectal cancer. J Cancer Res Clin Oncol. 2019;145(2):471-7.

42. Nozawa H, Morikawa T, Kawai K, Hata K, Tanaka T, Nishikawa T, et al. Obstruction is associated with perineural invasion in T3/T4 colon cancer. Colorectal Dis. 2019;21(8):917-24.

43. Suzuki T, Suwa K, Ogawa M, Eto K, Kawahara H, Fujita T, et al. Adjuvant chemotherapy for the perineural invasion of colorectal cancer. J Surg Res. 2015;199(1):84-9.

44. Vergara-Fernandez O, Navarro-Navarro A, Rangel-Rios HA, SalgadoNesme N, Reyes-Monroy JA, Velazquez-Fernandez D. Oncological implications of lymph nodes retrieval and perineural invasion in colorectal cancer: outcomes from a referral center. Rev Invest Clin. 2018;70(6):291-300.

45. Liebig C, Ayala G, Wilks J, Verstovsek G, Liu H, Agarwal N, et al. Perineural invasion is an independent predictor of outcome in colorectal cancer. J Clin Oncol. 2009;27(31):5131-7.

46. Yang Y, Huang X, Sun J, Gao P, Song Y, Chen X, et al. Prognostic value of perineural invasion in colorectal cancer: a meta-analysis. J Gastrointest Surg. 2015;19(6):1113-22.

47. van Hooft JE, van Halsema EE, Vanbiervliet G, Beets-Tan RG, DeWitt JM, Donnellan $F$, et al. Self-expandable metal stents for obstructing colonic and extracolonic cancer: European Society of Gastrointestinal Endoscopy (ESGE) Clinical Guideline. Endoscopy. 2014;46(11):990-1053.

48. Jiang HH, Zhang ZY, Wang XY, Tang $X$, Liu HL, Wang AL, et al. Prognostic significance of lymphovascular invasion in colorectal cancer 
and its association with genomic alterations. World J Gastroenterol. 2019;25(20):2489-502.

49. Lim SB, Yu CS, Jang SJ, Kim TW, Kim JH, Kim JC. Prognostic significance of lymphovascular invasion in sporadic colorectal cancer. Dis Colon Rectum. 2010;53(4):377-84.

50. Al-Sukhni E, Attwood K, Gabriel EM, LeVea CM, Kanehira K, Nurkin SJ. Lymphovascular and perineural invasion are associated with poor prognostic features and outcomes in colorectal cancer: a retrospective cohort study. Int J Surg. 2017;37:42-9.

51. Liang P, Nakada I, Hong JW, Tabuchi T, Motohashi G, Takemura A, et al. Prognostic significance of immunohistochemically detected blood and lymphatic vessel invasion in colorectal carcinoma: its impact on prognosis. Ann Surg Oncol. 2007;14(2):470-7.

52. Skancke M, Arnott SM, Amdur RL, Siegel RS, Obias VJ, Umapathi BA. Lymphovascular invasion and perineural invasion negatively impact overall survival for stage II adenocarcinoma of the colon. Dis Colon Rectum. 2019;62(2):181-8.

53. Meguerditchian AN, Bairati I, Lagace R, Harel F, Kibrite A. Prognostic significance of lymphovascular invasion in surgically cured rectal carcinoma. Am J Surg. 2005;189(6):707-13.

54. Messenger DE, Driman DK, Kirsch R. Developments in the assessment of venous invasion in colorectal cancer: implications for future practice and patient outcome. Hum Pathol. 2012;43(7):965-73.

55. Sato T, Ueno H, Mochizuki H, Shinto E, Hashiguchi Y, Kajiwara Y, et al. Objective criteria for the grading of venous invasion in colorectal cancer. Am J Surg Pathol. 2010;34(4):454-62.
56. Sejben I, Bori R, Cserni G. Venous invasion demonstrated by orcein staining of colorectal carcinoma specimens is associated with the development of distant metastasis. J Clin Pathol. 2010;63(7):575-8.

57. Teixeira F, Akaishi EH, Ushinohama AZ, Dutra TC, Netto SD, Utiyama EM, et al. Can we respect the principles of oncologic resection in an emergency surgery to treat colon cancer? World J Emerg Surg. 2015;10:5.

58. van Halsema EE, van Hooft JE, Small AJ, Baron TH, Garcia-Cano J, Cheon $\mathrm{JH}$, et al. Perforation in colorectal stenting: a meta-analysis and a search for risk factors. Gastrointest Endosc. 2014;79(6):970-82.e7 (quiz 983.e2, 983.e5).

59. Lauro A, Binetti M, Vaccari S, Cervellera M, Tonini V. Obstructing left-sided colonic cancer: is endoscopic stenting a bridge to surgery or a bridge tonowhere? Dig Dis Sci. 2020;65(10):2789-99.

60. Jain SR, Yaow C, Ng CH, Neo V, Lim F, Foo FJ, et al. Comparison of colonic stents, stomas and resection for obstructive left colon cancer: a metaanalysis. Tech Coloproctol. 2020;24(11):1121-36.

61. Cao Y, Gu J, Deng S, Li J, Wu K, Cai K. Long-term tumour outcomes of self-expanding metal stents as 'bridge to surgery'for the treatment of colorectal cancer with malignant obstruction: a systematic review and meta-analysis. Int J Colorectal Dis. 2019b;34(11):1827-38.

\section{Publisher's Note}

Springer Nature remains neutral with regard to jurisdictional claims in published maps and institutional affiliations.
Ready to submit your research? Choose BMC and benefit from:

- fast, convenient online submission

- thorough peer review by experienced researchers in your field

- rapid publication on acceptance

- support for research data, including large and complex data types

- gold Open Access which fosters wider collaboration and increased citations

- maximum visibility for your research: over $100 \mathrm{M}$ website views per year

At BMC, research is always in progress.

Learn more biomedcentral.com/submissions 